\title{
HASRAT TOKOH WASKA DALAM TETRALOGI NASKAH ORKES MADUN KARYA ARIFIN C. NOER: SUATU KAJIAN PSIKOANALISIS
}

\author{
Despian Nurhidayat, Venus Khasanah, dan Siti Gomo Attas \\ Program Studi Sastra Indonesia, Universitas Negeri Jakarta \\ despiannurhidayat@gmail.com
}

\begin{abstract}
Abstrak
Penelitian ini bertujuan untuk mengetahui hasrat tokoh Waska dalam tetralogi Orkes Madun karya Arifin C. Noer. Penelitian ini bersifat kepustakaan dan tidak terkait oleh tempat. Penelitian dilaksanakan pada bulan Oktober hingga Juli 2017. Objek penelitian ini adalah tokoh Waska dalam tetralogi naskah Orkes Madun. Fokus penelitian ini adalah hasrat tokoh Waska dalam tetralogi naskah Orkes Madun dengan subfokus penokohan dan perwatakan tokoh Waska dalam tetralogi naskah Orkes Madun, pergerakan hasrat tokoh Waska dalam tetralogi naskah Orkes Madun, dan hasrat memiliki (anaklitik) dan hasrat menjadi (narsistik) tokoh Waska dalam tetralogi naskah Orkes Madun. Teori yang digunakan adalah teori psikoanalisis hasrat oleh Jacques Lacan dan teori struktural naskah drama oleh Herman J. Waluyo. Metode yang digunakan dalam penelitian ini adalah metode deskriptif kualitatif dengan teknik analisis isi. Metode ini menggunakan tabel analisis sebagai alat bantu peneliti dan menggambarkan hasil penelitian analisis isi data. Tahap analisis dilakukan dengan menganalisis penokohan dan perwatakan tokoh Waska dan menganalisis hasrat memiliki (anaklitik) aktif atau pasif dan hasrat menjadi (narsistik) aktif atau pasif. Hasil penelitian menunjukkan tokoh Waska memiliki hasrat memiliki (anaklitik) aktif dalam tetralogi naskah Orkes Madun. Hasrat tokoh Waska dipengaruhi oleh perannya disetiap naskah. Hasrat tokoh Waska yang merupakan hasrat memiliki (anaklitik) akan mengambil alih ketika ia menjadi tokoh sentral (DN).
\end{abstract}

Kata kunci: Psikoanalisis, Hasrat, Penokohan dan Perwatakan, Tetralogi Naskah Orkes Madun, Arifin C. Noer.

\section{PENDAHULUAN}

Drama sudah lama dikenal di kalangan masyarakat Indonesia sejak tahun 1800-an. Sejak itulah masyarakat Indonesia sudah diperkenalkan dengan sajian drama yang salah satunya dibawakan oleh Teater Stamboel. Teater Stamboel merupakan salah satu komunitas teater yang memulai masa perintisan awal perkembangan drama di Indonesia (Riantiarno, 2011: 26). Hingga saat ini, pertunjukan drama atau teater masih sering disukai oleh seluruh kalangan masyarakat. Animo terhadap pertunjukan drama atau teater cukup besar. Hal ini 
terlihat dari adanya pementasan teater rutin oleh berbagai macam grup teater di Indonesia. Pementasan ini diadakan di TIM (Taman Ismail Marzuki) setiap bulannya. Para pegiat teater Indonesia pun mempunyai pengaruh yang cukup besar bagi perkembangan drama di Indonesia dengan naskah-naskah yang mereka buat, terjemahan, atau adaptasi dari naskah luar. Pegiat teater itu antara lain: WS Rendra dengan Bengkel Teater, N. Riantiarno dengan Teater Koma, Putu wijaya dengan Teater Mandiri, dan Arifin C. Noer dengan Teater Kecil.

Berbicara mengenai pegiat teater atau biasa disebut dramawan, Arifin C. Noer merupakan salah satu tokoh penting dalam perkembangan drama di Indonesia. Arifin C. Noer lahir di Cirebon tanggal 10 Maret 1941 dan meninggal pada tanggal 28 Mei 1995 karena penyakit lever. Selama masa hidupnya, Arifin C. Noer telah memberikan banyak sumbangsih dalam kesenian baik berupa drama, film, puisi, maupun esai-esai budaya. Para pegiat teater bahkan beranggapan bahwa Arifin C. Noer merupakan salah satu pelopor dan pembaruan teater di Indonesia. Kehadiran Arifin C. Noer memberikan corak fenomena tersendiri dalam hal bentuk dan gaya pengucapan yang sama sekali baru dalam dunia teater Indonesia. Dalam wawancara bersama Arifin C. Noer, Hadjid Hamzah seorang editor sekaligus wartawan dari redaktur majalah Minggu Pagi, begitu kagum terhadap diri Arifin C. Noer.

"Hidup Arifin memang adalah puisi. Adalah drama. Masih di SMP dia, dan dia telah bergerak di RRI. Di pentas. Di Majalah. Di SMA dia "bertengkar" seru dengan gurunya (yang mengajar soal-soal drama) mengenai pentas. Justru dia dikeluarkan dari SMA kelas 1 karena dia banyak main di pentas! Begitulah Arifin. Berpuluh kali dia main drama. Berpuluh kali dia menyutradarai. Dan dia selalu tak puas. Selalu setiap memainkan repertoire Indonesia merasa belum mencurahkan seluruh kemampuannya. "Sebab repertoire-repertoire Indonesia itu belum memberikan chalenge yang berat bagi saya," begitu dikatakan Arifin. Dan karena kesadaran inilah, tangan Arifin selalu bergerak. Bergerak, bergerak, bergerak menulis drama. Dia tulis drama-drama modern. Dia luangkan pikiran-pikirannya pada pentas, puisi, pentas, puisi. Dan telah dia selesaikan tidak kurang dari 17 naskah drama! Padahal umurnya baru 25 tahun. Padahal pernah dikatakan kepada saya: "Terus terang Djid, semuanya masih jelek nilainya. Tapi Insya Allah, kelak akan ada juga naskah yang baik dari saya." Arifin memang selalu tak puas! Dia selalu mencari, mencari, mencari dan mencari dalam gelisahnya (Hamzah, 1966: 12)." 
Arifin C. Noer mendirikan Teater Kecil ketika hijrah ke Jakarta pada tahun 1968. Arifin C. Noer sering memenangkan penghargaan atas karyanya, beberapa penghargaannya yaitu Pemenang pertama sayembara penulisan lakon Teater Muslim “Mega Mega”, Pemenang kedua sayembara naskah drama (1967), Anugerah Seni dari pemerintah RI (1971), dan Pemenang pertama sayembara penulisan lakon DKJ naskah drama "Kapai Kapai” (1972). Arifin C. Noer memang dikenal sebagai penulis naskah absurd. Beberapa naskahnya dijadikan objek penelitian absurditas dikarenakan banyak hal yang perlu dipikirkan ulang ketika membaca naskahnya. Beberapa naskah Arifin C. Noer antara lain: KapaiKapai (1970), Tengul (1973), Madekur dan Tarkeni, Atawa Orkes Madun (1974), Umang-Umang (1976), Sandek Pemuda Pekerja (1979).

Berbicara persoalan naskah, naskah dari Arifin C. Noer yang cukup fenomenal adalah Orkes Madun. Naskah Orkes Madun sendiri masih sering dipentaskan oleh berbagai komunitas teater di Indonesia sampai saat ini. Bahkan sering sekali naskah Orkes Madun dimainkan di FTJ (Festival Teater Jakarta). Naskah Orkes Madun sendiri sebenarnya ingin dibuat pentalogi. Namun, karena Arifin C. Noer meninggal, ia hanya menyelesaikan naskah Ozone dan hingga saat ini naskah Orkes Madun hanya menjadi naskah tetralogi. Orkes Madun sendiri merupakan naskah yang menceritakan kehidupan kelompok pencuri, perampok, pelacur, dan anak-anak jalanan yang dipimpin oleh Waska.

Naskah pertama dari tetralogi Orkes Madun adalah Madekur dan Tarkeni. Naskah ini menceritakan romansa antara seorang pencuri dan seorang pelacur. Hubungan mereka tidak direstui oleh kedua orang tuanya, walaupun akhirnya mereka memaksakan kehendak untuk tetap bersama. Naskah ini mengisahkan bagaimana kondisi masyarakat kalangan bawah yang digambarkan oleh seorang pelacur dan pencuri. Dalam naskah inilah awal kemunculan dari tokoh Waska, sang 'rosul kejahatan' yang mempunyai banyak pengikut setia. Dalam naskah ini peran Waska cukup penting karena ia dimintai saran oleh Madekur dan Tarkeni yang sedang dalam keadaan gundah gulana.

Beralih ke naskah Umang-Umang, yang mengangkat kisah dari kehidupan Waska yang tengah menghadapi kematiannya. Namun, ia belum ingin mati karena 
masih ingin mengurusi umang-umangnya (para pengikutnya). Kemudian, ia mendapatkan cara agar dapat menjadi abadi dan terhindar dari kematiannya. Cara itu pun ia lakukan dan berhasil membuat Waska hidup abadi bersama dengan beberapa pengikut setianya. Dalam naskah ini keinginan Waska untuk hidup abadi terlihat sangat kuat.

Berbeda dari dua naskah sebelumnya, naskah Sandek sendiri mengisahkan tentang anak Waska bernama Sandek yang diakui oleh Waska dengan cara dibaptis dengan siksaan. Sandek merupakan anak buruh pabrik serta menjalani kehidupan pabrik. Dalam naskah ini lebih menceritakan bagaimana kejamnya kehidupan pabrik yang dijalani Sandek. Waska tetap muncul dalam naskah ini, walaupun pada akhirnya ia pergi ke luar angkasa untuk menjalani kematiannya.

Naskah terakhir yaitu Ozone mengisahkan kematian Waska setelah menjalani hidup sekian lamanya dan ia begitu menderita dengan keabadiannya. Dalam naskah ini dikisahkan bahwa Waska telah hidup beribu-ribu tahun di luar angkasa. Waska yang tadinya mempunyai keinginan hidup yang besar justru berbalik memohon agar ia bisa mati. Dalam naskah ini terlihat sangat jelas bahwa keinginan Waska berubah dari naskah sebelumnya, yaitu Umang-Umang.

Dalam keempat naskah Arifin C. Noer ini selalu menghadirkan tokoh Waska. Dalam setiap naskah pun, Waska selalu menjadi tokoh penting yang tidak dapat dikesampingkan begitu saja. Terdapat kejanggalan dalam keempat naskah ini. Seperti dalam naskah Umang-Umang Waska tidak mengharapkan kematiannya, tetapi dalam naskah Ozone Waska ingin dirinya tenang dalam kematian. Inilah salah satu yang menjadi alasan mengapa tokoh Waska menarik untuk dapat diteliti. Untuk melihat apa yang sebenarnya Waska inginkan peneliti menggunakan pendekatan psikoanalisis Jaques Lacan.

Jaques Lacan yang berprofesi sebagai psikoanalis pada tahun 1950 mengembangkan pandangan psikoanalisisnya dengan didasarkan pada berbagai gagasan yang diartikulasikan dalam antropologi dan linguistik strukturalis. Lacan terinspirasi dari tokoh-tokoh seperti Freud dan Saussure. Kemudian ia mencoba untuk menggabungkannya. Bahkan Lacan juga dipengaruhi oleh pemikiranpemikiran filsafat Heidegger, Levi Straus, dan Derrida. Dari hasil "perenungan” 
Lacan tentang psikoanalisis ia menginterpretasikan Freud menggunakan teori strukturalis dan postrukturalis. Lacan kemudian mengalihkan psikoanalisis yang secara hakikatnya bersifat humanis menjadi teori atau filsafat psikoanalisis. Lacan terkenal dengan teorinya struktur ketidaksadaran manusia yang menyerupai bahasa. Ia dianggap sebagai salah satu ahli psikologi dan filsafat yang paling kontroversial setelah kematian Freud. Ia melihat bahwa realita atau kenyataan dapat diungkapkan dari penggunaan bahasa. Teorinya mengenai psikologi ini merupakan bentuk pengembangan diri dari teori Freud yang sebelumnya terkonsentrasi pada aspek ketidaksadaran manusia. Hasrat sendiri dapat dikatakan sebagai konsep pemikiran dari Jacques Lacan. Hasrat adalah intisari manusia, hasrat merupakan jantung eksistensi manusia, sekaligus perhatian utama ilmu psikoanalisa.

Tokoh Waska sendiri sangat unik dengan karakternya yang sangat begitu kuat. Namun, dalam penelitian ini bukan hal itu yang akan diperdalam lebih jauh, melainkan hasrat sebenarnya dari tokoh Waska. Hal ini pun dapat dikaji menggunakan teori hasrat dari Jacques Lacan. Melihat bahwa keinginan Waska yang ingin hidup abadi dalam Umang-Umang dengan keinginannya untuk mati dalam Ozone berbanding terbalik, maka perlu dianalisa apa sebenarnya hasrat yang dimiliki oleh Waska dalam tetralogi naskah Orkes Madun karangan Arifin C. Noer, sehingga dapat terlihat jelas apa sebenarnya hasrat yang diinginkan oleh Waska. Penelitian yang berkaitan dengan naskah Orkes Madun sendiri pun sudah banyak dilakukan, namun belum ada yang melakukan analisis terhadap tokoh Waska dengan menggunakan objek empat naskah Orkes Madun.

\section{METODOLOGI PENELITIAN}

Penelitian ini memiliki tujuan untuk mengetahui hasrat tokoh Waska dalam tertalogi naskah Orkes Madun. Lingkup penelitian ini adalah tokoh Waska dalam tetralogi naskah Orkes Madun. Metode yang digunakan adalah deskriptif kualitatif dengan teknik analisis isi. Kriteria analisis dalam penelitian ini adalah menentukan penokohan dan perwatakan tokoh Waska, mengungkap pergerakan hasrat yang terdapat pada dialog tokoh Waska, mengategorikan jenis hasrat 
(narsistik atau anklitik) yang terdapat pada dialog tokoh Waska, menentukan (aktif atau pasif) jenis hasrat (narsistik atau anaklitik) yang terdapat pada dialog tokoh Waska.

\section{HASIL DAN PEMBAHASAN}

Hasrat adalah sesuatu hal yang merubah keinginan menjadi kebutuhan. Hasrat muncul karena dipacu adanya kekurangan yang belum bisa tercukupi. Menurut Lacan Hasrat dibagi menjadi dua, yaitu hasrat menjadi (narsistik) dan hasrat memiliki (anaklitik).

Hasrat menjadi atau narsistik merupakan hasrat yang membuat seseorang yang berhasrat tertentu untuk menjadi bentuk ideal dari hasrat yang mereka inginkan. Sedangkan hasrat memiliki atau anaklitik adalah hasrat untuk memiliki atau mendapatkan sesuatu yang disukai untuk kebaikan atau kesejahteraan diri sendiri maupun orang lain. Hasrat anaklitik dan narsistik mengambil bentuk aktif dan pasif karena perbedaan tujuan antara yang aktif dan pasif.

Tokoh Waska adalah tokoh yang sangat menarik untuk diteliti mengenai hasratnya. Ia merupakah tokoh besar yang diciptakan Arifin C Noer dalam tetralogi Orkes Madun. Waska merupakan seorang 'rosul kejahatan', atau bisa disebut bapak kejahatan bagi manusia kelas bawah.

Hasrat tokoh Waska dalam tetralogi Orkes Madun bergerak bergantian antara hasrat menjadi (narsistik) dengan hasrat memiliki (anaklitik). Dalam naskah Madekur dan Takeni. Hasrat Waska lebih dominan bergerak pada hasrat menjadi (narsistik). Dalam naskah Umang-Umang. Hasrat Waska lebih dominan bergerak pada hasrat memiliki (anaklitik). Dalam naskah Sandek Pemuda Pekerja. Hasrat tokoh Waska lebih dominan bergerak pada hasrat menjadi (narsistik). Dan dalam naskah Ozone. Hasrat Waska lebih dominan bergerak pada hasrat memiliki (anaklitik).

Waska memiliki hasrat yang sangat penting dalam keempat naskah ini. Karena hasratnya mempengaruhi jalannya cerita. Dalam naskah Madekur dan Tarkeni, Waska meperlihatkan gejolak hasrat akan identitasnya sebagai tokoh yang besar. Identitas tokoh Waska yang merupakan pemimpin dari Umang- 
Umang diperkuat dengan adanya hasrat narsistik, hal ini ditunjukkan dengan dialog-dialog yang mengagungkan dirinya dan menganggap besar dirinya. Hasrat Waska ini disebut hasrat narsistik yang aktif, karena dalam naskah ini Waska menyadari akan hasratnya sendiri agar ia bisa menjadi seorang tokoh yang diagungkan. Dalam naskah ini, peran tokoh Waska sebagai tokoh pembantu atau pelengkap mempengaruhi terbentuknya hasrat. Hal ini menyebabkan tokoh Waska hanya mendapatkan sedikit dialog dibandingkan dengan tokoh Madekur atau tokoh Tarkeni yang merupakan tokoh sentral dalam naskah tersebut. Waska yang merupakan tokoh pembantu dalam naskah Madekur dan Tarkeni memperlihatkan adanya hasrat narsistik aktif untuk membuat dirinya menjadi tokoh yang penting dan besar dalam naskah ini.

Berbeda dengan naskah sebelumnya, dalam naskah Umang-Umang tokoh Waska menjadi tokoh sentral dan memperlihatkan hasrat untuk mendapatkan kehidupan yang lebih panjang. Hasrat ini disebut dengan hasrat anaklitik yang aktif, karena dalam naskah ini Waska mempunyai sebuah rencana perampokkan semesta dan rencananya ini dihalangi oleh realita bahwa ia akan segera menemui ajalnya dikarenakan umurnya yang sudah tua, dan karena hal tersebut Waska berhasrat untuk memiliki kehidupan yang lebih panjang agar ia bisa menjalankan rencananya itu untuk mencapai kepuasan batinnya. Peran tokoh Waska sebagai tokoh yang sentral menimbulkan terbentuknya hasrat anaklitik aktif yang menunjukkan bahwa dengan hasratnya ini mempengaruhi jalannya cerita karena perannya yang sebagai tokoh sentral.

Beda halnya dengan naskah Madekur dan Tarkeni dan Umang-Umang, peran Waska dalam naskah Sandek Pemuda Pekerja menjadi tokoh Utama dalam cerita. Sebagai tokoh utama, tokoh Waska membentuk hasrat untuk tetap menjadi seorang tokoh yang diagungkan dan besar agar ia terlihat memiliki peran yang cukup penting dalam naskah ini dan bisa disebut hasrat narsistik aktif. Beda dengan perannya dalam naskah Madekur dan Tarkeni, tokoh Waska mempunyai intensitas dialog yang cukup banyak, dan dalam naskah ini peran Waska menjadi penentang tokoh Sandek untuk tidak melakukan kesalahan yang ia lakukan. 
Dalam naskah terakhir, yaitu Ozone tokoh Waska menjadi tokoh sentral setelah di naskah Sandek Pemuda Pekerja ia menjadi tokoh Utama. Berbeda dengan hasrat yang muncul di naskah Umang-Umang, Waska di sini memiliki hasrat untuk mendapatkan kematiannya setelah ia menjadi abadi di dalam naskah Umang-Umang, ia menginginkan kematian yang dulu tidak ia harapkan. Hasrat Waska disini merupakan hasrat anaklitik aktif, yaitu hasrat untuk memiliki kematian demi ketentraman jiwanya.

Hasrat tokoh Waska jika dilihat dari tetralogi naskah Orkes Madun, merupakan hasrat anaklitik. Hasrat ini membuat dirirnya menjadi tokoh yang menginginkan kematian dan kehidupan untuk dirinya hasrat ini terlihat dalam naskah Umang-Umang dan naskah Ozone. Bukan hanya itu, hasrat ini juga membentuk watak tokoh Waska yang egois dan berambisi penuh pada perubahan keadaan sosial untuk kehidupan Umang-Umang. Hasrat anaklitik ini dipengaruhi pula oleh perannya sebagai tokoh sentral yang mengatur jalannya cerita.

Arifin C. Noer tetap mempertahankan eksistensi tokoh Waska dalam tetralogi Orkes Madun, walaupun di dalam naskah Madekur dan Tarkeni tokoh Waska sebenarnya sudah mati ditembak oleh seseorang. Hal ini membuat peneliti menyimpulkan bahwa dalam naskah Madekur dan Tarkeni, tokoh Waska merupakan tokoh yang dibuat berdasarkan ketidaksengajaan pengarang. Tokoh Waska yang sebenarnya merupakan cerminan dari tokoh Semar dibuat menjadi tokoh yang dipenuhi oleh kejahatan. Arifin menyadari potensi tokoh Waska yang bisa dikembangkan lebih jauh lagi yang menyebabkan tokoh Waska dibangkitkan kembali di naskah Umang-Umang. Hasrat tokoh Waska dipengaruhi oleh perannya dalam setiap naskah. Yang berarti tokoh Waska memiliki hasrat anaklitik ketika ia menjadi tokoh sentral, dan jika Waska bukan tokoh sentral, hasrat narsistik akan terlihat pada tokoh Waska untuk mempertahankan eksistensinya dan tetap membuatnya menjadi tokoh yang besar. Tokoh Waska selalu memiliki hasrat penting yang menyebabkan kehadirannya tidak bisa dianggap sebagai tokoh yang hanya sebagai figuran saja.

Hasrat tokoh Waska merupakan pemahaman konsep tentang "diri” yang dilihat melalui unsur bahasa. Hasrat berdiam dalam diri manusia dan hasrat 
merupakan resistensi dari sifat manusia yang pada dasarnya selalu mengalami kekurangan. Tokoh Waska pun merupakan tokoh yang melihat dirinya sebagai tokoh yang selalu menemui kekurangan dan menginginkan perubahan dalam hidupnya.

\section{KESIMPULAN}

Setelah melakukan analisis terhadap tetralogi Orkes Madun karya Arifin C. Noer dengan menganalisis hasrat tokoh Waska dalam tetralogi Orkes Madun tersebut. Dapat disimpulkan sebagai berikut:

1. Tokoh Waska memiliki peran masing-masing didalam tetralogi naskah ini. Dalam naskah Madekur dan Tarkeni, tokoh Waska hanya menjadi tokoh pembantu sekaligus tokoh tritagonis. Dalam naskah Sandek Pemuda Pekerja, tokoh Waska menjadi tokoh utama sekaligus tokoh antagonis. Dalam naskah Umang-Umang dan Ozone, tokoh Waska menjadi tokoh sentral sekaligus tokoh protagonis.

2. Hasrat tokoh Waska dalam tetralogi Orkes Madun bergerak secara dinamis, saling bergantian antara hasrat memiliki (anaklitik) dan hasrat menjadi (narsistik).

3. Dalam tetralogi naskah ini, secara garis besar hasrat tokoh Waska merupakan hasrat memiliki (anaklitik) dan mengambil bentuk aktif, yaitu hasrat untuk memilik kehidupan dan kematian untuk kepuasan pribadinya semata.

4. Peran tokoh Waska dalam tetralogi naskah Orkes Madun selalu berganti, namun perannya sebagai tokoh sentral mempengaruhi hasratnya menjadi hasrat anaklitik aktif.

\section{Daftar Pustaka}

Barry, Peter. 2010. Beginning Theory: Pengantar Komprehensif Teori Sastra dan Pengantar Budaya. Yogyakarta: Jalan Sutra. 
Bracher, Mark. 2004. Jacques Lacan, Diskursus, dan Perubahan Sosial: Kritik Budaya Psikoanalisis. Jakarta: Jalasutra.

Budianta, Melani. 2008. Membaca Sastra (Pengantar Memahami Sastra untuk Perguruan Tinggi). Magelang: Indonesia Tera.

Eagletown, Mary, (ed). 1991. Feminist Literary Criticism. New York: Longman Inc.

Evans, Dylan. 1996. An Introductory Dictionary of Lacanian Psychoanalysis.

Hamzah, Hadjid. 1966. "Omong-omong dengan Arifin C Noer" Minggu Pagi. Yogyakarta.

Hill, Philip. 2002. Lacan untuk Pemula. Yogyakarta: Kanisius.

https://profil.merdeka.com/indonesia/a/arifin-chairin-noer/

Lacan, Jacques. 1949. The Mirror Stage as Formative of the Function of the I as Revealed in Psychoanalytic Experience. UK: Routledge.

-------. 1973. The Four Fundamental Concepts of Psychoanalysis, Editions du seuil.

-------. 1977. Ecrits: A Selection. London: Tavistock.

Riantiarno, N. 2011. Kitab Teater. Jakarta: Grasindo.

Waluyo, Herman J. 2002. Drama: Teori dan pengajarannya. Yogyakarta: PT. Hanindita Graha Widya.

www.bandarnaskah.blogspot.com (Diunduh pada 11 Oktober 2016) Kumpulan naskah Arifin C. Noer.

Zulfahnur, dkk. 1996. Teori Sastra. Jakarta: Departemen Pendidikan dan Kebudayaan. 